\title{
SYNDACTYLOPOIESIS: A SIMPLE OPERATION FOR INTERDIGITAL SOFT CORN
}

\author{
E. H. Strach and M. S. Cornah, Liverpool, England \\ From Whiston and St Helens Hospitals, Liverpool
}

Soft corn, also known as interdigital clavus or tyloma molle, typically occurs between the fourth and fifth toes. Although a minor condition it can be extremely painful. We are uncertain of the incidence of soft corn because such patients usually present mainly to the chiropodist and only occasionally to the orthopaedic surgeon.

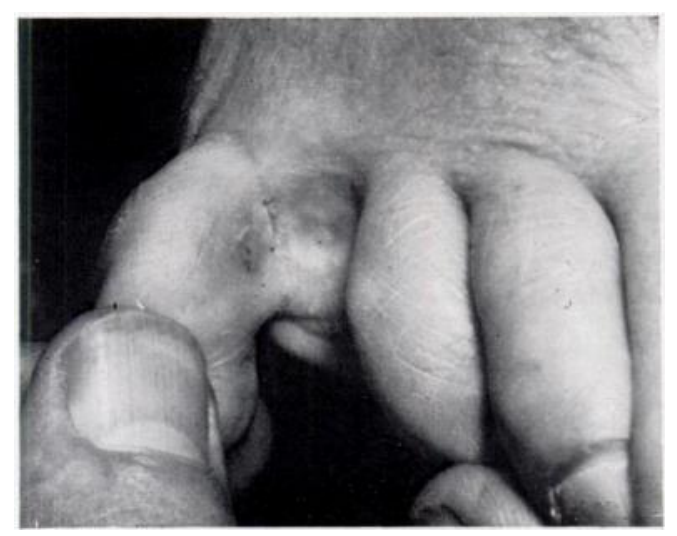

FIG. 1

A typical interdigital corn.

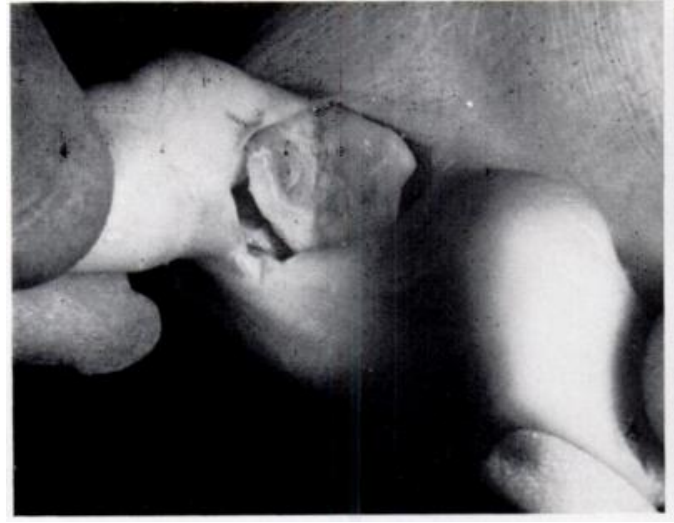

FIG. 2

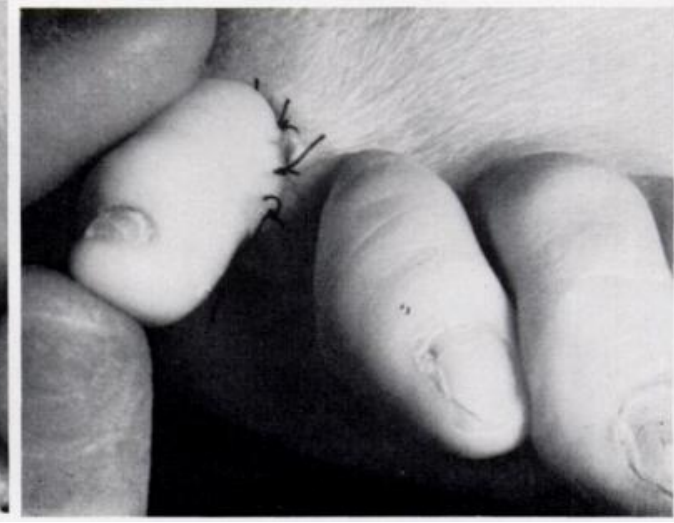

Fig. 3

Figure 2-Excision of the interdigital cleft. Figure 3-The appearance after skin suture.

The corn is usually situated over the medial aspect of the base of the little toe (Fig. 1) and the surrounding skin is macerated by sweat. The cleft between the fourth and fifth toes appears to be deeper than normal. The lesion results from pressure by a rather prominent head of the proximal phalanx of the fifth toe, and possibly also from a prominent lateral condyle of the base of the proximal phalanx of the fourth toe (Margo 1967). 
We have been concerned in cases which have proved refractory to simple conservative measures by the chiropodist. We have used an operation, the principle of which is to excise the deep cleft between the two toes, including the soft corn. The resulting defect is closed by a simple syndactylising procedure.

\section{TECHNIQUE OF OPERATION}

A curved incision is made over the medial aspect of the little toe just distal to the corn, and a similar incision is made over the lateral aspect of the fourth toe, meeting the first incision on the plantar and dorsal aspects of the web (Fig. 2). After removal of the skin the cut edges are sutured to form a new web. It is surprising how normal the resulting web appears considering the amount of skin removed (Fig. 3). A light pressure dressing is applied, care being taken to avoid pulling the two toes apart. The sutures are removed at ten days with similar precautions. Occasionally the wound is a little moist, but heals completely within a few days.

\section{COMMENT}

We have found this procedure entirely satisfactory in twelve cases.

Several other operations have been described for this condition. Excision of the underlying bony prominences of the fourth or the fifth toes was advocated by Margo (1967) and Brahms (1967). We consider that this is unnecessary and that it is simpler to remove the skin that is being trapped between the two bony prominences. Haboush and Martin (1947) advocated a rather elaborate plastic procedure which they themselves considered a radical method of treatment for such a minor lesion.

We wish to thank Mr M. Bayliss for the photographic work.

\section{REFERENCES}

Brahms, M. A. (1967): Common Foot Problems. Journal of Bone and Joint Surgery, 49-A, 1653.

Haboush, E. J., and Martin, R. V. (1947): Painful Interdigital Clavus (Soft Corn). Journal of Bone and Joint Surgery, 29, 756.

Margo, M. K. (1967): Surgical Treatment of Conditions of the Fore Part of the Foot. Journal of Bone and Joint Surgery, 49-A, 1665. 